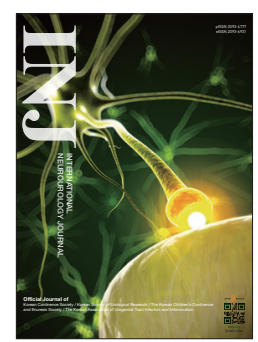

\title{
Erratum: Author name correction
}

Int Neurourol J 2016;20:168-168

http://dx.doi.org/10.5213/inj.1620err.001

pISSN 2093-4777 • eISSN 2093-6931

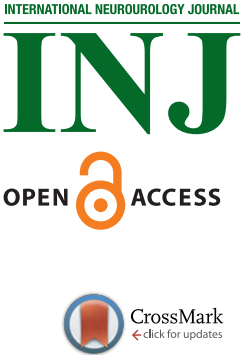

\section{Extracellular Matrix Revisited: Roles in Tissue Engineering}

\author{
Youhwan Kim¹, Hyojin Ko ${ }^{1}$, Ik Keun Kwon², Kwanwoo Shin ${ }^{1}$ \\ ${ }^{1}$ Department of Chemistry and Institute of Biological Interfaces, Sogang University, Seoul, Korea \\ ${ }^{2}$ Department of Dental Materials, School of Dentistry, Kyung Hee University, Seoul, Korea
}

Int Neurourol J 2016;20 Suppl 1:S23-29

http://dx.doi.org/10.5213/inj.1632600.318

In this article, the 3rd author's name was misprinted unintentionally. The name should be corrected as follows:

\section{- Corrected 3rd author's name}

Il Keun Kwon 